\title{
Life Expectancy and Inequalities Therein by Income From 2016 to 2018 Across the 253 Electoral Constituencies of the National Assembly of the Korea
}

\author{
Jinwook Bahk' ${ }^{1}$, Hee-Yeon Kang², Young-Ho Khang ${ }^{2,3}$ \\ ${ }^{1}$ Department of Public Health, Keimyung University, Daegu, Korea; ${ }^{2}$ Department of Health Policy and Management, Seoul National University \\ College of Medicine, Seoul, Korea; ${ }^{3}$ Institute of Health Policy and Management, Seoul National University Medical Research Center, Seoul, Korea
}

Objectives: We calculated life expectancy and inequalities therein by income for the period of 2016-2018 across the 253 electoral constituencies of the 20th National Assembly election in Korea.

Methods: We obtained population and death data between 2016 and 2018 from the National Health Information Database and constructed abridged life tables using standard life table procedures according to gender and income quintiles for the electoral constituencies of the 20th National Assembly election held in 2016.

Results: Life expectancy across the 253 constituencies ranged from 80.51 years to 87.05 years, corresponding to a gap of 6.54 years. The life expectancy difference by income across the 253 constituencies ranged from 2.94 years to 10.67 years. In each province, the difference in life expectancy by income across electoral constituencies was generally greater than the inter-constituency differences. Constituencies in capital and metropolitan areas showed a higher life expectancy and a lower life expectancy difference by income than constituencies in rural areas.

Conclusions: Pro-rich inequalities in life expectancy by income existed in every electoral constituency in Korea. Both intra-constituency and inter-constituency socioeconomic inequalities in health should be highlighted in future policy-making in the National Assembly.

Key words: Life expectancy, Geography, Socioeconomic factors, Korea

\section{INTRODUCTION}

Geographical regions are an important factor to consider when comparing the overall health and health equity of a population. In Korea, life expectancy and socioeconomic in-

Received: February 20, 2020 Accepted: March 3, 2020

Corresponding author: Young-Ho Khang, MD, PhD Department of Health Policy and Management, Seoul National University College of Medicine, 103 Daehak-ro, Jongno-gu,

Seoul 03080, Korea

E-mail: yhkhang@snu.ac.kr

This is an Open Access article distributed under the terms of the Creative Commons Attribution Non-Commercial License (https://creativecommons.org/licenses/bync/4.0// which permits unrestricted non-commercial use, distribution, and reproduction in any medium, provided the original work is properly cited. equalities in life expectancy have been explored at the level of administrative districts (i.e., si, gun, and gu, corresponding to cities, counties, and districts, respectively) [1-3]. Information on population health and health inequalities in each local administrative district would constitute an important instrument for policy leaders and local government officials to enhance awareness of related problems and to develop and implement policies with the aim of improving health and enhancing health equity. Meanwhile, National Assembly members elected from local constituencies could play a major role in developing various local policies and programs affecting population health and health inequalities. However, parliamentary electoral constituencies and administrative districts are not identical in Korea. Information on life expectancy and its inequalities 
in each local administrative district may not be relevant to $\mathrm{Na}$ tional Assembly members or candidates in an election. In other words, calculations of life expectancy according to administrative districts are relevant for the health of people living within that administrative jurisdiction, while calculations of life expectancy at the level of electoral constituencies are relevant for the health status of the communities that elect specific political representatives. Life expectancy and inequalities in life expectancy by income across electoral constituencies could therefore be very important information, both to voters and to National Assembly members and candidates, especially ahead of a general election. In this study, we report life expectancy and inequalities in life expectancy by income for the period of 2016-2018 across the 253 electoral constituencies of the 20th National Assembly election held in 2016.

\section{METHODS}

We used population and death data between 2016 and 2018 from the National Health Information Database (NHID) provided by the National Health Insurance Service [4]. The NHID data cover the entire population of Korea, including National Health Insurance beneficiaries and Medical Aid recipients, except for foreigners. The NHID data have been reported to be comparable to data from Statistics Korea for calculating mortality at the national, provincial, and district levels [5]. Using the NHID data, inequalities in life expectancy by income have been explored in prior Korean studies [2,3,6].

For this study, aggregate population and death data without personal identification numbers according to gender, age $(0$, $1-4,5-9,10-14, \ldots, 80-84$, and $85+)$, and income quintiles according to the electoral constituencies of the 2016 National Assembly election were obtained from the NHID. An electoral constituency is a district that elects a member of the National Assembly. Supplemental Material 1 presents the number of the population and the number of deaths by gender between 2016 and 2018 in each of the electoral constituencies. We used National Health Insurance premiums as a proxy for income, as has been done in previous research [3,6-9]. We calculated age group-specific equivalized income, taking household size into account, and categorized equivalized income into quintiles at the nearest quintile points within each electoral constituency. Thus, the income quintiles for each electoral constituency were calculated based on the income distribution in each constituency, rather than the income distribution of the Korean total population. Using the numbers of population and deaths by gender and age groups, we constructed abridged life tables using standard life table procedures according to income quintiles [10]. We employed the Kannisto-Thatcher method to expand the open-ended age interval $85+$ to estimate the probability of dying for the 5 -year age groups of $85-89,90-94, \ldots$, 120-124, and 125+ [11]. In Supplemental Material 2, we provide detailed information on life expectancy between 2016 and 2018 according to gender and income in the electoral constituencies of the 20th National Assembly election held in 2016 in Korea. In addition, we provide lists of the 20 constituencies with the lowest life expectancy and the 20 constituencies with the highest life expectancy differences between the lowest and highest income quintiles in Supplemental Materials 3 and 4.

\section{Ethics Statement}

This study was approved by the National Health Insurance Service of Korea (No. NHIS-2020-1-098) and the Seoul National University Hospital Institutional Review Board (IRB No. E-2002016-1098).

\section{RESULTS}

Table 1 presents the distribution of life expectancy and interquintile income differences in life expectancy (defined as the difference in life expectancy between the top and bottom income quintiles) according to gender across the 253 electoral constituencies. The mean and median values for life expectancy (for men and women combined) in the 253 electoral constituencies were 82.90 years and 82.71 years, respectively, which approximated the national life expectancy in 2017 reported by Statistics Korea ( 82.70 years). Life expectancy ranged from 80.51 years to 87.05 years across the electoral constituencies, corresponding to a life expectancy gap of 6.54 years. The life expectancy gap between the top and bottom electoral constituencies was greater in men $(85.05$ years minus 76.69 years $=$ 8.36 years) than in women ( 89.33 years minus 83.52 years $=$ 5.81 years). On average, the life expectancy difference between the top and bottom income quintiles was approximately 7.00 years (mean, 6.96; median, 6.95) across the 253 electoral constituencies. The constituency with the smallest difference in life expectancy between the top and bottom income quintiles had a 2.94-year gap, while the constituency with the greatest difference had a 10.67-year gap. The life expectancy gap by income was generally greater in men than in women. When we 
Table 1. Life expectancy distribution by gender and income (for the period of 2016-2018) across the 253 electoral constituencies of the 2016 National Assembly election

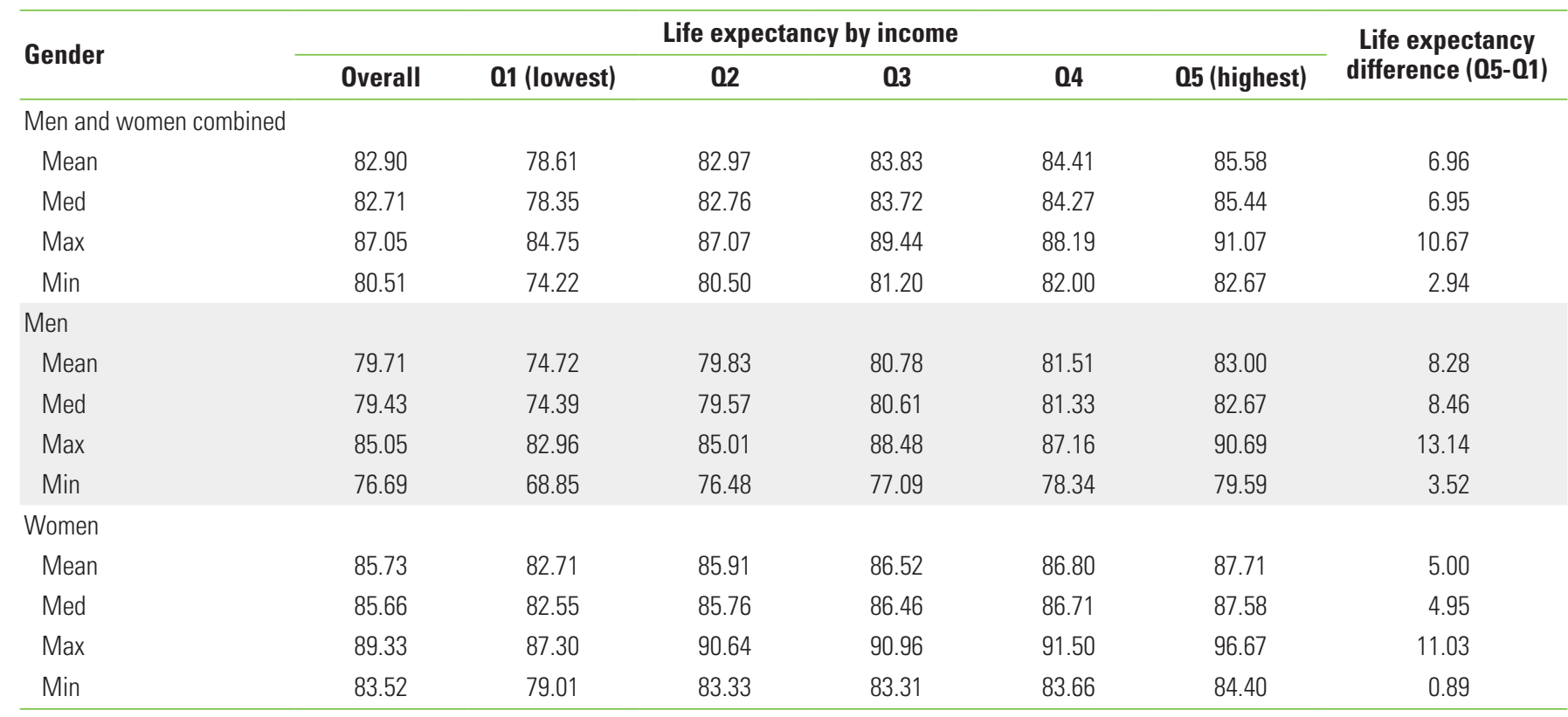

Med, median; Max, maximum; Min, minimum.

examined life expectancy and differences in life expectancy by income in each province, the life expectancy differences within each constituency by income were greater than those among constituencies (Supplemental Material 2 for more detailed information on each constituency in each province).

Figure 1 presents a visualization of the distribution of life expectancy (for the period of 2016-2018) across the 253 electoral constituencies. In general, overall life expectancy was high in the capital area (shown in blue), and non-capital rural areas showed a low life expectancy (shown in red). Figure 2 presents the life expectancy difference between the lowest and highest income quintiles (Q5-Q1) for each electoral constituency. The life expectancy difference by income in each constituency was calculated as the difference in life expectancy between the top and bottom income quintiles in that constituency. The distribution of income-based differences in life expectancy showed similar patterns to those displayed in Figure 1. In general, electoral constituencies with a lower life expectancy had larger life expectancy gaps by income. Supplemental Materials 5-21 show more detailed visualizations of the distributions of life expectancy and income-based differences in life expectancy by provincial areas, showing that the life expectancy differences by income across electoral constituencies in a province were generally greater than inter-constituency differences in life expectancy.

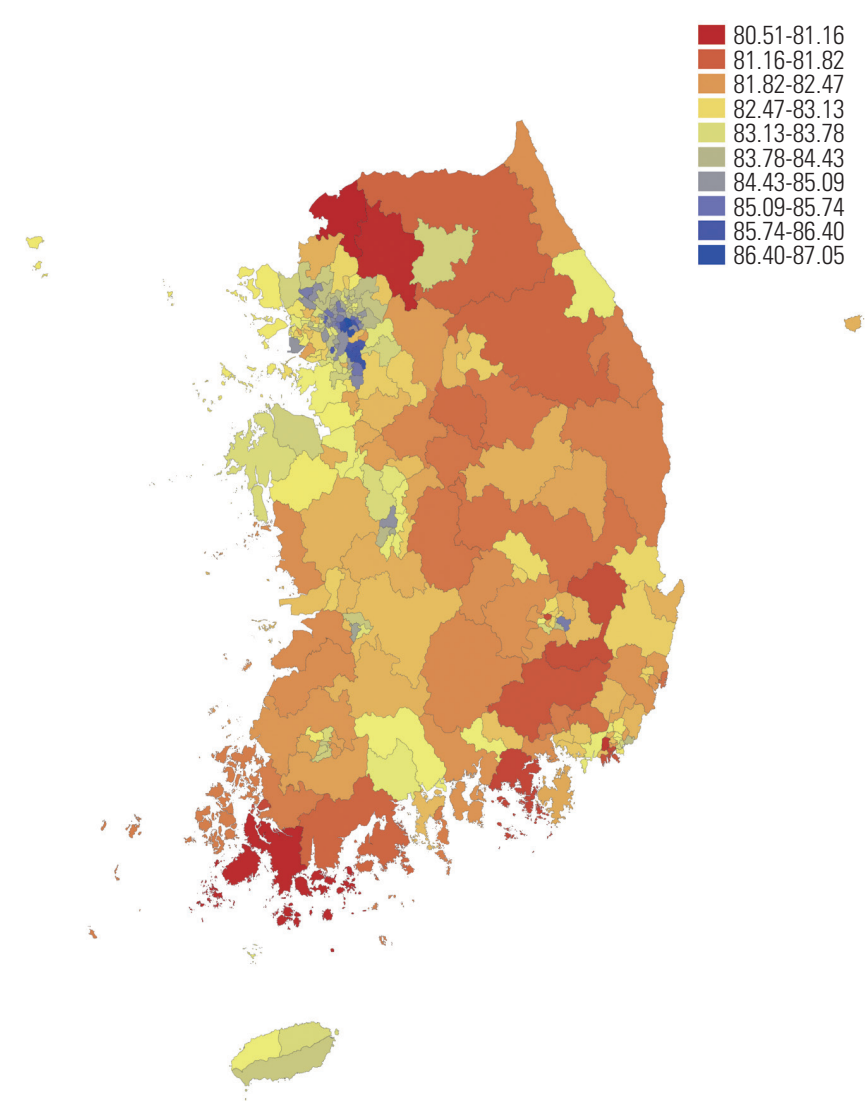

Figure 1. Life expectancy distribution (for the period of 20162018) across the 253 electoral constituencies of the $2016 \mathrm{Na}$ tional Assembly election in Korea. 


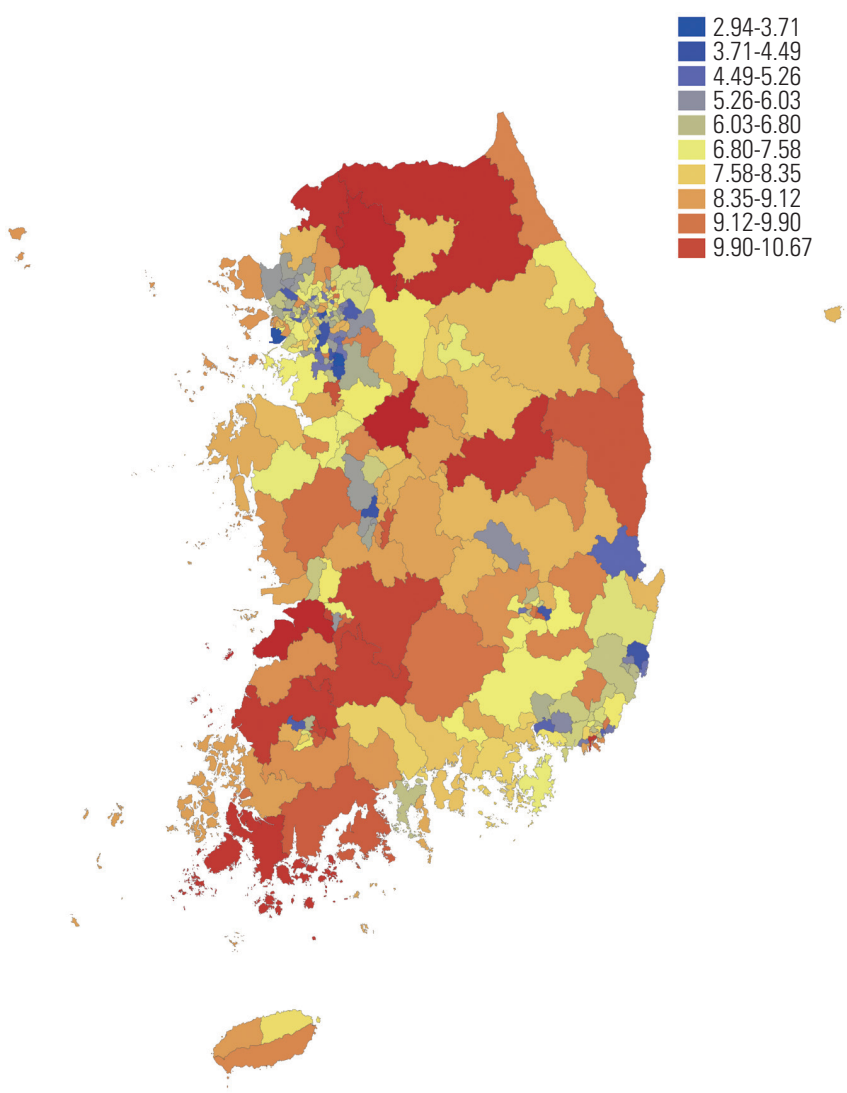

Figure 2. Differences in life expectancy (for the period of 2016-2018) between the lowest and highest income quintiles (Q5-Q1) across the 253 electoral constituencies of the 2016 National Assembly election.

\section{DISCUSSION}

In this study, we presented life expectancy and life expectancy gaps by income for the period of 2016-2018 across the 253 electoral constituencies of the 20th National Assembly election held in 2016. At the time of data acquisition and analysis, the electoral constituencies for the 21th National Assembly election had not been finalized, but only a minor change in the electoral constituencies is expected for the 21th National Assembly election. The results of this study clearly show that differences in life expectancy between the lowest and highest income quintiles existed in every electoral constituency. Moreover, a wider variation was observed for income-based differences in life expectancy across constituencies compared to the differences in life expectancy across neighboring constituencies. These patterns were also observed at the provincial level. For example, the range (maximum minus minimum) of life expectancy was 4.22 years across 49 constituencies in the
Seoul metropolitan area, while the mean and median values for life expectancy differences between the top and bottom income quintiles among the 49 electoral constituencies in Seoul were 6.37 years and 6.24 years, respectively (Supplemental Material 2 for more detailed values). These results indicate that the disparities in income-based differences in life expectancy within electoral constituencies were generally larger than the disparities in life expectancy between electoral constituencies. Therefore, intra-constituency inequalities in health should be further highlighted in future policy-making processes, in addition to inter-constituency inequalities.

This study also showed that rural areas had a lower life expectancy and higher life expectancy gaps by income than capital and metropolitan areas. Rural areas have been persistently marginalized with the concentration of economic development in capital and metropolitan areas [12,13]. Rural areas are more likely to have insufficient health resources than urban areas [14] and tend to have older populations with a lower socioeconomic status [15]. Prior Korean studies on life expectancy across administrative districts in 2010-2015 showed similar results to those of this study, although the magnitude of the differences in life expectancy and life expectancy by income quintiles across administrative districts was about 1 year greater than the inequalities observed across electoral constituencies [1,2].

This is the first study in Korea to calculate life expectancy and life expectancy gaps by income at the electoral constituency level. National Assembly members can improve population health and reduce health inequalities through legislative activities. Considering the major health inequalities in Korea, legislative actions should be proactively taken to reduce regional disparities in life expectancy and income inequalities in life expectancy within electoral constituencies. It is our hope that the findings of this study will be useful for lawmakers in developing legislation to reduce health inequalities. It should be noted that this study did not explore the association between voting patterns and health status; however, studies from the United Kingdom have reported on the association between voting patterns and mortality in the context of British general elections in the 1980s and 1990s [16-18]. In the United Kingdom, a negative association between voting for the Conservative Party and mortality and a positive association between abstention and mortality were found. The relationships of health inequalities with the abstention rate or support for a particular political party remain a topic for further research.

In conclusion, this study provided evidence that pro-rich in- 
equalities in life expectancy by income existed in every electoral constituency of the National Assembly in Korea. Both intraconstituency and inter-constituency socioeconomic inequalities in health should be highlighted in future policy-making in the National Assembly.

\section{SUPPLEMENTAL MATERIALS}

Supplemental materials are available at https://doi.org/10. 3961/jpmph.20.050.

Korean version is available at https://doi.org/10.3961/jpmph. 20.050 .

\section{CONFLICT OF INTEREST}

The authors have no conflicts of interest associated with the material presented in this paper.

\section{FUNDING}

This work was supported by a grant of the Korea Health Technology R\&D Project through the Korea Health Industry Development Institute (KHIDI), funded by the Ministry of Health and Welfare, Republic of Korea (grant No.: HI18C0446), and a National Research Foundation of Korea (NRF) grant funded by the Korean government (MSIP; No. 2017R1C1B5017747).

\section{ACKNOWLEDGEMENTS}

None.

\section{AUTHOR CONTRIBUTIONS}

Conceptualization: YHK. Data curation: HYK. Formal analysis: JB. Funding acquisition: YHK. Methodology: YHK, JB. Project administration: YHK. Visualization: JB, HYK. Writing - original draft:YHK. Writing - review \& editing: JB, HYK.

\section{ORCID}

Jinwook Bahk https://orcid.org/0000-0002-7715-9955

Hee-Yeon Kang https://orcid.org/0000-0001-8530-8087

Young-Ho Khang https://orcid.org/0000-0002-9585-8266

\section{REFERENCES}

1. Korean Society for Equity in Health. Health gap profiles at the national, provincial, district levels [cited 2020 Jan 28]. Available from: https://drive.google.com/open?id=1Czdweu2_Db5QsKJOiqSGo1BJp2ody0nl (Korean).

2. Khang YH, Lim D, Bahk J, Kim I, Kang HY, Chang Y, et al. A publicly well-accepted measure versus an academically desirable measure of health inequality: cross-sectional comparison of the difference between income quintiles with the slope index of inequality. BMJ Open 2019;9(6):e028687.

3. Lim D, Bahk J, Ock M, Kim I, Kang HY, Kim YY, et al. Income-related inequality in quality-adjusted life expectancy in Korea at the national and district levels. Health Qual Life Outcomes 2020; 18(1):45.

4. Seong SC, Kim YY, Khang YH, Heon Park J, Kang HJ, Lee H, et al. Data resource profile: the National Health Information Database of the National Health Insurance Service in South Korea. Int J Epidemiol 2017;46(3):799-800.

5. Bahk J, Kim YY, Kang HY, Lee J, Kim I, Lee J, et al. Using the National Health Information Database of the National Health Insurance Service in Korea for monitoring mortality and life expectancy at national and local levels. J Korean Med Sci 2017; 32(11):1764-1770.

6. Khang YH, Bahk J, Lim D, Kang HY, Lim HK, Kim YY, et al. Trends in inequality in life expectancy at birth between 2004 and 2017 and projections for 2030 in Korea: multiyear cross-sectional differences by income from National Health Insurance data. BMJ Open 2019;9(7):e030683.

7. Jung-Choi K, Khang YH, Cho HJ. Socioeconomic differentials in cause-specific mortality among 1.4 million South Korean public servants and their dependents. J Epidemiol Community Health 2011;65(7):632-638.

8. Khang YH, Bahk J, Yi N, Yun SC. Age- and cause-specific contributions to income difference in life expectancy at birth: findings from nationally representative data on one million South Koreans. Eur J Public Health 2016;26(2):242-248.

9. Khang YH, Yang S, Cho HJ, Jung-Choi K, Yun SC. Decomposition of socio-economic differences in life expectancy at birth by age and cause of death among 4 million South Korean public servants and their dependents. Int J Epidemiol 2010;39(6): 1656-1666.

10. Preston SH, Heuveline P, Guillot M. Demography: measuring and modeling population processes. Malden: Blackwell Publishers; 2001, p. 42-63. 
11. Thatcher AR, Kannisto V, Vaupel JW. The force of mortality at ages 80 to 120. Odense: Odense University Press; 1998, p. 1-80.

12. Kim IK. Socioeconomic concentration in the Seoul metropoli$\tan$ area and its implications in the urbanization process of Korea. Korean J Sociol 2010;44(3):111-128.

13. Hashiya H. Urbanization in the Republic of Korea and Taiwan: a NIEs pattern. Dev Econ 1996;34(4):447-469.

14. Cho HJ. Equity in health care: current situation in South Korea. J Korean Med Assoc 2013;56(3):184-194 (Korean).

15. Hong JM, Lee SH, Shin HS. Variation in life expectancy by area deprivation: magnitude and trends in Korea, 2000-2011. Health Soc Sci 2013;33:273-298 (Korean).

16. Smith GD, Dorling D. "I'm all right, John": voting patterns and mortality in England and Wales, 1981-92. BMJ 1996;313(7072): 1573-1577.

17. Davey Smith G. Association between voting patterns and mortality remains. BMJ 1997;315(7105):430-431.

18. Dorling D, Smith GD, Shaw M. Analysis of trends in premature mortality by Labour voting in the 1997 general election. BMJ 2001;322(7298):1336-1337. 